\title{
Фактор «умной силы» \\ в процессах институционализации \\ международных отношений ${ }^{1}$
}

\author{
С.В. Михневич
}

Михневич Сергей Владимирович - аспирант кафедры мировой политики факультета мировой экономики и мировой политики Национального исследовательского университета «Высшая школа экономики»; Российская Федерация, 115419, Москва, ул. Орджоникидзе, 8; E-mail: sxzex@yandex.ru

Статья посвящена анализу роли фактора «умной силы» в процессах институциональных изменений в межкдународных отношениях, их основных элементов и движущих сил, а также значения взаимодействий по проблемам «силы» в эволюции международной системы и подсистем.

Сегодня наблюдается очередной виток трансформации среды международных отношений благодаря радикальному расширению возможностей для трансграничного взаимодействия отдельных сообществ и общественных групп. Результатом этого может являться формирование новой идентичности, существующей вне государственных грании. Широкая практика трансграничных контактов, помимо прочего, способствует серьезному повышению роли факторов ценностей и идеологии на международной арене. При этом в роли фона для трансформации среды международных отношений выступают процессы глобализации, которые, в свою очередь, обостряют проблемы «трех ключевых разрывов»: экономико-социального, политического и ценностного. В конечном счете происходит экспоненциальный рост неопределенности 8 мировой политике и серьезное ослабление международных возможностей государств. Одним из наиболее действенных средств структурирования взаимодействий и элиминирования неопределенности является формирование комплексных институциональных структур. Кроме того, они отражают убеждения и ценности, сформировавшиеся в обществах и сообществах в ходе исторического развития. Таким образом, создание соответствующих институтов способно существенно облегчить многие существующие международные проблемы, в том числе связанные с изменением среды. При этом крайне важно обеспечить взаимовыгодное сочетание и взаимоучет интересов всех участвующих акторов. В противном случае эффективность создаваемых систем будет невелика.

Рассматривавщееся ослабление международных позиций государств как ключевых акторов проявляется также и в снижении эффективности ресурса «жесткой силь» в реализации государствами своих национальных интересов. Происходит постоянное увеличение значения ресурса «мягкой силы», которая сама по себе также не является эффективным механизмом прямого действия на политику других государств. Более результативным и корректным средством представляется политика «умной силы», которая сочетает в себе «жесткую силу» для понуждения и возмездия и «мягкую силу» в виде убеждения и притяжения. Способности актора в реализации «умной силы» тесно связаны с контекстуальным интеллектом и существующими «эффектами колеи», коренящимися в культуре и историческом опыте, которые формируют особенности общественного познания и восприятия тех или иных событий и явлений. Вышеуказанные факторы оказывают непосредственное воздействие на формирование международных институциональных структур.

В контексте анализа функций отдельных аспектов «умной силы» автор обращает внимание на кониепцию «трех лиц силь». Также в статье отмечается определяющее значение безопасности в международных процессах (институционализации), которая лежит практически в основе всех ключевых решений, принимаемых элитами в ходе процессов дефинизации ${ }^{2}$. При этом повышение безопасности может трак-

${ }^{1}$ Указанная работа подготовлена в рамках Научно-учебной группы «США и глобальное управление» (НИУ ВШЭ). Материал поступил в редакцию в феврале 2015 г.

2 Дефинизация (авт.) - процесс принятия решений в отношении национальных интересов, формулирования и решения ключевых задач, выбора способов и инструментов их разрешения 
товаться как снижение неопределенности в ее отношении, в том числе за счет институционализации взаимодействий и реализации коллективной «умной силь».

Ключевые слова: «умная сила», «мягкая сила», «жесткая сила», неопределенность, культура, стратегия, институциональные изменения, дефинизация, секьюритизация, безопасность, КНР, Китай, АСЕАН, США, Юго-Восточная Азия, Азиатско-Тихоокеанский регион, АТР

\section{Введение}

Все происходит так, как происходит, потому что многое происходит одновременно.

Г. Колодко. «Мир в движении»³

Современная наука о мировой политике неоднократно обращалась к проблемам изменения среды международных взаимодействий. Данная тема затрагивалась в работах таких корифеев, как Джозеф Най, Роберт Кохейн, Стивен Краснер, Бьорн Хеттне, Майкл Манн, и десятков и сотен менее известных ученых по всему миру, представляющих совершенно разные направления теории международных отношений. Во множестве работ процесс трансформации международных отношений в мировую политику рассматривался в различных преломлениях и разрезах.

Однако на ряд важных вопросов ответить до сих пор не удалось. Среди них не последнее место занимают следующие. Как соотносится изменение среды международных взаимодействий с сохранением роли и влияния государства на международной арене? Какими ресурсами и механизмами оно может воспользоваться? Как обеспечить «управляемое воздействие» на трансформацию или поддержание эффективного функционирования существующих институтов в своих интересах? С какими сложностями придется столкнуться и какими критериями необходимо руководствоваться в выработке адекватной и корректной политики?

Нахождение ответа на указанные вопросы будет не только представлять значительный научный интерес, но и может способствовать существенному повышению эффективности международной политики страны.

Снижение неопределенности в существующих международных взаимодействиях являет собой одну из ключевых целей всей международной активности государств. Для достижения этой цели они предпринимают различные действия, в том числе связанные с формированием эффективных и адаптивных институциональных структур. Разумеется, отдельные институты отвечают интересам некоторых участников более, чем других. И созданию таких условий, которые позволят относительно улучшить свои позиции в неустойчивой, «рыхлой» среде, подчинены практически все шаги государств на международной арене. Однако в ряде случаев этому препятствует доминирование в страновой повестке идеологических или ценностных максим, не нацеленных на максимизацию преимуществ. И этот момент также должен учитываться, ввиду того, что в противном случае сформировать эффективные институциональные структуры для решения общезначимых задач, не удастся.

и накопления необходимых ресурсов, а также оценки достигнутых результатов и определения новых стратегических целей и задач, в соответствии с которым в основе целеполагания лежат приоритеты обеспечения безопасности в разносрочных перспективах.

${ }^{3}$ Колодко Г. Мир в движении. М.: Магистр, 2009. 
Более того, ценностное измерение также должно учитываться и при выработке политики в отношении действующих структур. Изменение повестки дня отдельных акторов может поставить под угрозу эффективность целого института, если он не отличается высокой адаптивностью. Соответственно, возникает задача по повышению институциональной адаптивности. В условиях существенной системной инерции изменение среды и стратегических целей акторов может поставить под угрозу существование даже крупных институциональных структур. Теоретически можно заметить, что в случае, если институт утрачивает свои способности решать задачи, ради чего он был создан, ему на смену должен прийти новый, более эффективный. Однако далеко не факт, что новые структуры будут таковыми. Наряду с существенным усилением неопределенности в переходный период, дополнительные проблемы может создать неспособность действующих сил достичь согласия относительно создаваемой структуры. В таком случае наличие действующих договоренностей, достигнутых даже в отдаленном прошлом, позволяет поддерживать и развивать взаимодействия во многих ключевых сферах.

Таким образом, достижение стратегического баланса между процессами институционального созидания и разрушения на международной арене представляет собой одну из стратегических макроцелей государств как международных акторов. «Институциональные провалы» ${ }^{4}$ могут проявляться в снижении общей эффективности сотрудничества и управляемости отдельных подсистем и глобальной системы в целом. Результатом также может стать падение общего уровня безопасности. Соответственно, важной задачей является ликвидация подобных «институциональных провалов».

Полагаем, что одним из способов сохранения определяющего международного положения государств является реализация политики «умной силы». В рамках настоящей статьи делается попытка соотнести проблемы институциональных трансформаций в условиях существенной эрозии среды международных взаимодействий и высокой неопределенности с применением политики «умной силы». Проведение данной политики может способствовать как повышению общей эффективности институтов, так и формированию новых траекторий их развития. Ее конечным результатом будет формирование условий для максимизации комплексной мощи соответствующих акторов. Сама политика «умной силы» подразумевает корректное и адекватное, а зачастую и творческое, применение всей гаммы и всего спектра имеющихся ресурсов. Не будет лишним отметить, что ключевым направлением ее приложения является сфера безопасности, что вносит определенные коррективы в формирование стратегии. Трансформация институтов под воздействием «умной силы» может ставить задачу повышения безопасности актора за счет снижения неопределенности и максимизации ресурсов в целях разрешения ключевых угроз, вызовов и рисков и создания условий для реализации ключевых интересов.

В качестве примеров для анализа в работе используется обращение к опыту акторов из «незападных регионов», в частности АТР. Это связано с тем, что большая часть различных форм международных взаимодействий сегодня протекает на территориях таких регионов, существенно отличающихся по своим культурно-историческим и ценностным основам и опыту от наиболее развитых государств Запада. Изучение опыта подобных взаимодействий позволит расширить возможности по прогнозированию развития международной среды в будущем, оценить его перспективы и обозначить ключевые проблемные поля и механизмы решения.

${ }^{4}$ «Институциональные провалы» представляют собой сферы, не имеющие соответствующих структур, способствующих налаживанию конструктивного мультиакторного взаимодействия. 


\section{Современный этап трансформации международной системы: фактор неопределенности и роль институтов в ее преодолении}

Повсеместное распространение новейших средств пространственно-временного сжатия (средства ПВС), таких как телевидение, мобильная связь и Интернет, в частности социальных сетей, создало уникальные возможности для объединения различных групп людей, живущих в разных странах и регионах. Произошло уменьшение «барьеров для входа» в мировую политику. Говоря словами известного американского социолога Майкла Манна, наблюдается ослабление «эффекта клетки» - способности государств «захватывать» социальных акторов [Манн, 2014, с. 85]. Государства более не могут удерживать значительные группы акторов, что транспонируется и на международный уровень.

Необходимым условием протекания процесса объединения наряду с технической составляющей являются общие ценности как основа диалога и самоидентификации. «Процесс самоидентификации состоит в различии внутреннего и внешнего, в исключении одних элементов окружающего мира и присвоении других» [Морозов, 2009, c. 11]. Постепенное воздействие воспринимаемых образов и идей трансформирует ценностную ориентацию отдельных членов общества и его всего в целом. В конечном счете может формироваться новая идентичность, не имеющая отношения к соответствующему государству и способная оказывать негативное влияние на его возможность достигать максимального результата в реализации определенных им целей.

Изменение природы международных отношений также связано с комплексом процессов, сопровождающих современный этап глобализации. Мы наблюдаем новый этап трансформации глобальной экономической системы, в рамках которой существуют страны на разных этапах социально-экономического развития. При этом растет разрыв в реальной производительности и эффективности экономических систем (не только в «финансомике»), но, что более важно, в уровнях благосостояния населения. Одновременно наличие примерно равного доступа к информации создает условия для «экстримизации» - накаливания отношений между разными обществами, в рамках которых и между которыми появляются новые транснациональные сообщества. Разумеется, можно вспомнить о концепции цифрового разрыва, в соответствии с которым существует серьезная разница в доступе к информации в развитых и развивающихся государствах [DiMaggio, Hargittai, 2001]. Но так сложилось, что культуры государств, отстающие в плане цифрового неравенства, чаще являются коллективистскими культурами, в которых информация, полученная одним индивидом в ходе практики коммуникаций, оперативно становится доступна членам его сообщества.

В целом же можно выделить «три ключевых разрыва» на современном этапе глобализации, затрагивающих базовые интересы населения:

1. Экономико-социальный разрыв, проявляющийся в растущей разнице в уровне жизни групп населения внутри отдельных государств и территорий и между разными странами.

2. Политический разрыв, находящий отражение в невозможности на приемлемом и желаемом уровне реализовать собственные политические и экономические права, а также обеспечить приемлемый уровень и механизм управления.

3. Ценностный разрыв, значение которого серьезно растет за счет его показательности и демонстративности, порой становящимися casus belli в мировой политике. Более того, ценностный разрыв становится основной причиной «сращивания» 
и интеграции обществ и групп населения различных в транснациональном масштабе, часто «поперек» существующих границ.

Процессы глобализации проявляются, прежде всего, в неограниченной конкуренции и требуют от экономических субъектов повышения эффективности всех видов операций. Именно поэтому глобализация ущемляет интересы менее развитых стран и их народов. В современном государстве люди выступают в трех ключевых общественных ролях: потребители - производители - граждане [Колодко, 2011, с. 57]. На международной арене опосредованно через комплекс общественных отношений это проявляется в трех схожих ролях государств: потребители - производители - участники мирополитических взаимодействий ${ }^{5}$. Соответственно, для государств остро стоит задача формирования баланса между своими ролями и другими государствами, их национальными интересами в каждой из этих ролей. Фактически одним из показателей успешности государства на международной арене является способность обеспечить приемлемый взаимоучет и адекватную сбалансированность своих национальных интересов, национальных интересов других государств и интересов международной системы/подсистемы.

Ситуация существенно усложняется как раз тем, что вестфальский принцип вынесения ценностей «за скобки» международных отношений больше не работает. Ценности становятся определяющим фактором в мировой политике, формируя особое идейное измерение мировой политики. Это позволяет обществам и отдельным общественным объединениям становиться новыми участниками мировой политики. Как пишет лауреат Нобелевской премии по экономике Дуглас Норт: «Эволюция человеческого общества направляется представлениями игроков, выбор совершается в свете этих представлений с намерением добиться результатов, снижающих неопределенность. Источником этих представлений служит то, во что игроки верят: теории, предотвращающие последствия их поступков и обычно неотделимые от их предпочтений» [Норт, 2010, с. 8]. Практически изменения, затрагивающие политическую, экономическую и социальную сферы, являются процессами, формируемыми представлениями участников о последствиях их действий. А «доминирующие убеждения, т.е. те, которые разделяют политические и экономические предприниматели, способные определять политику, со временем вырастают в структуру институтов, определяющих экономическое и политическое поведение» [Норт, 2010, с. 15].

Складывающаяся в итоге институциональная матрица накладывает серьезные ограничения на возможности выбора для лидеров, которые пытаются модернизировать существуюшие или создать новые институты для того, чтобы улучшить свои экономические или политические позиции, снижая неопределенность. По мнению Ф. Найта, «...риск - состояние, в котором имеется возможность получить распределение вероятностей исходов таким образом, чтобы застраховать их. Неопределенность - состояние, в котором такого распределения возможностей не существует. Неопределенность не является отклонением от нормы, это фундаментальное условие, ответственное за развитие структуры социальной организации в ходе истории и в доисторические времена» [Knight, 1921].

Как полагает Н. Талеб, существуют разные виды неопределенности (неизвестности): «известная неопределенность» - «когда мы знаем, что чего-то не знаем», и «неиз-

${ }^{5}$ Мы обращаемся к термину «мировая политика» как более емкому по сравнению с термином «международные отношения», который включает в себя исключительно межгосударственные отношения. Мировая политика же включает в себя в том числе взаимодействие на международной арене акторов негосударственного типа. 
вестная неопределенность» - когда «мы не знаем, что чего-то не знаем» [Талеб, 2009, c. 211-213, с. 257]. «Известная неопределенность» может выступать в роли источника предсказуемого поведения для актора, обладающего соответствующей информацией об отсутствии данных относительно тех или иных значимых факторов. Сторона, принимающая решение, может моделировать и пытаться реализовывать те или иные сценарии с учетом понимания имеющихся информационных лакун. «Неизвестная неопределенность» же является основной проблемой при реализации политики, поскольку в случае ее проявления на разрешение возникающих проблем расходуется колоссальный объем ресурсов, в том числе и потому, что очень часто отсутствует понимание ее серьезности и возможных последствий. Фактически проведение политики «умной силы», о которой речь пойдет дальше, непосредственно связано с «управлением неопределенностью». Оно подразумевает уменьшение неопределенности или ее перевод в состояние «известной» в отношении собственной политики актора и генерацию «неизвестной неопределенности» в приемлемых зонах для соперничающих центров силы.

Тем не менее в целом одной из ключевых макроцелей всей деятельности людей является именно снижение общего уровня неопределенности. Проблема в том, что ограничения, накладываемые на структуры социальной, политической и экономической организации с целью снижения неопределенности, в свою очередь при объединении в едином конструкте становятся источниками новой неопределенности. Серьезная проблема связана также с интерпретацией неопределенности, поскольку «за горизонтом» могут скрываться не только существенные проблемы, но и выгодные шансы.

По мнению Д. Норта, «люди пытаются использовать свои представления о мире для структурирования окружающей действительности таким образом, чтобы снизить неопределенность в отношениях с другими людьми» [Норт, 2010, с. 20]. Однако практически сразу возникает вопрос: чьи именно представления имеют значение и как они могут быть переведены в трансформацию окружающей человека действительности? Д. Норт считает, что это зависит от институциональной структуры, которая является «комбинацией формальных правил, неформальных ограничений и особенностей их выполнения» [Норт, 2010, с. 20]. Причем сами особенности выполнения обусловлены существующей системой стимулов, механизмами побуждения (принуждения) и особенностями процесса понимания/познания. Структура отношений между людьми определяет, кто выступает в роли лидера, чей выбор играет главную роль, и то, как сделанный выбор реализуется посредством решений, управляющих соответствующей структурой.

Таким образом, взаимодействие между людьми определяется институтами, создающими системы стимулов, управляющие поведением людей. «Институт - это система правил, убеждений, норм и организаций, которые совместно порождают регулярность социального поведения», - пишет Авнер Грейф [Грейф, 2013, с. 56]. «Различные испытания, сквозь которые проходят общества с течением времени, ведут к возникновению различных представлений об устройстве мира и, соответственно, требуют различных институтов для создания одних и тех же стимулов» [Норт, 2010, с. 104]. Таким образом, институциональная структура отражает убеждения и ценности, сформировавшиеся в обществе в ходе его исторического развития. Можно достаточно уверенно говорить о том, что между системами убеждений и институциональной структурой существует тесная взаимозависимость. «Системы убеждений включают в себя внутреннюю репрезентацию социального ландшафта. Институты являются теми структурами, которые люди накладывают на этот ландшафт для получения желаемого результата» [Норт, 2010, c. 80]. Не менее важно, что внутренняя взаимосвязь между убеждениями и института- 
ми, находящая отражение в формальных правилах, еще более точно зафиксирована в неформальных институтах, таких как мораль, нормы, конвенции и кодексы поведения. Некоторые из этих неформальных институтов содержат универсальные кодексы систем поведения, общие для разных культур, в то время как другие имеют уникальные черты, характерные для разных культур, формальные элементы институциональной структуры могут корректироваться с учетом решений лиц, чьи системы убеждений играют определяющую роль в соответствующих структурах. Но неформальные институты очень часто не подвержены «прямым приказам» и потому более устойчивы.

Подытоживая эту часть статьи, хотелось бы отметить, что трансформационные процессы, протекающие сегодня в международной системе, генерируют повышенные риски для устойчивого и предсказуемого функционирования всех ее участников. В ряде случаев речь идет о появлении крупных зон неопределенности как в территориальном плане - например, проблемы реализации суверенитета, так и в отдельных направлениях и сферах взаимодействия - например, эрозия режима нераспространения ядерного оружия. Вопрос в том, как справиться с расширением неопределенности и усложнением международной системы и сохранить ее в устойчивом состоянии, способствующем формированию условий для прогрессивного поступательного развития разных частей света.

\section{Преимущества и недостатки «жесткой» и «мягкой» сил в поддержании эффективности политики государства на международной арене}

Различные интересы, ценности, а порой и «мировоззрения» «старых» и «новых» акторов приводят к нарастанию конфликтного потенциала из-за увеличения неопределенности в отношении учета интересов отдельных участников, а также размера их относительных и абсолютных выгод. Значительные достижения альтернативных центров силы в сфере политики или экономики могут приводить к повышению привлекательности их моделей развития для других акторов, имевших ранее иные ориентиры. В результате создаются серьезные проблемные поля, решение которых не всегда возможно в рамках существующих международных структур, как формальных (международные организации, соглашения), так и нет (международные правовые режимы, негласные соглашения и правила поведения).

Одновременно снижается значимость «жесткой силы» государства, его военнополитического могущества [Михневич, 2015]. «Жесткая сила» зависит от многих параметров, в том числе от возросших затрат на единицу (человеческую) из-за растущего жизненного уровня и изменяющегося менталитета людей, что накладывается на серьезную нехватку человеческих ресурсов. Ситуацию с «жесткой силой» сегодня можно выразить следующей фразой Франсуа Эйсбура: «Есть возможность нанести удар, но нет возможности закрепить успех» [Эйсбур, 2013]. На сегодняшний день «жесткая сила» практически не используется для удержания власти над захваченной территорией. Объектом «жесткой силы» выступают именно государства, постепенно теряющие возможность контролировать динамику трансграничных коммуникаций, испытывая эрозию суверенитета. По этой причине они нуждаются в средстве, которое позволит им сохранять свою эффективность, оставаться основными и деятельными игроками на международной арене, не превращаясь в «пустую институциональную оболочку».

Таким средством является политика «мягкой силы», включающая в себя три базовых компонента: привлекательность системы ценностей государства, привлекатель- 
ность его культуры, эффективность невоенных механизмов внешней политики [Nye, 2004 , p. 11]. Объектом «мягкой силы» является не государство, но его народ, общество. В этом ее фундаментальное отличие от «жесткой силы». Постепенное воздействие воспринимаемых образов и идей трансформирует ценностную ориентацию отдельных членов обшества и его всего в целом. В дальнейшем это корректирует механизмы восприятия действительности, повышая (или понижая) в глазах членов общества привлекательность того или иного государства, его политики, а также общественной системы [Михневич, 2014]. Если представить механизм распространения «мягкой силы» в виде схемы, то получится следующее [Михневич, 2015]:

1) экономические (или иные) успехи страны возбуждают к себе интерес в обществах стран-объектов ее «мягкой силы»;

2) в стране-объекте возникает потребность в изучении модели развития страны, в основе которой лежит ее культура;

3) распространение получают различные элементы культуры страны-субъекта, формируется обширный информационный фон в ее отношении;

4) происходит изменение восприятия имиджа страны-субъекта обществом страны-объекта (как правило, в сторону улучшения);

5) складываются условия для максимизации «мягкой силы» страны-субъекта.

Как справедливо замечает Н. Талеб, реакция людей «на информационный сигнал определяется не его логической насыщенностью, а тем, в какую структуру он встроен и как он взаимодействует с их социально-эмоциональной системой» [Талеб, 2009, с. 102]. «Мягкая сила» трансформирует данную систему в масштабе общества государстваобъекта или отдельных сообществ в интересах ее источника. В конечном счете «мягкая сила» может оказывать влияние и на функционирование государства как института. Но это влияние опосредовано, поскольку его субъектом уже является общество государства-объекта. Таким образом, «мягкая сила» не может выступать сама по себе в качестве эффективного средства (прямого воздействия) на государство как актора мировой политики [Михневич, 2015]. Ее распространение, как правило, связано не столько с целенаправленной политикой государства-субъекта, сколько с косвенным влиянием объективных и субъективных условий и результатов развития его общественной системы, экономическими и политическими успехами, их очевидностью и привлекательностью для обществ стран-объектов данного влияния [Михневич, 2014].

Стоит отметить, что в современной науке нет единообразия в классификации типов и видов силы. Так, российскими политологами С.А. Карагановым и Ф.А. Лукьяновым предложена следующая классификация понятия силы: сила оружия, сила денег, сила образов [Караганов, Лукьянов, 2013, с. 15-26]. Мы можем увидеть определенное сходство с разделением силы на «жесткую» и «мягкую», предлагаемую Дж. Наем. Но введение в классификацию дополнительного типа силы - «силы денег» - позволяет ввести в поле анализа целый комплекс отношений, который в противном случае остается «на вторых ролях» и рассматривается в прикладном ключе. Как справедливо отмечает М.В. Братерский, «в рамках понятийного аппарата теории международных отношений... сила - феномен, проявляющийся в системе межгосударственных политических взаимоотношений, таких как власть, принуждение, подчинение, конфликт» [Братерский, 2013, с. 167]. То есть сила является непременным атрибутом власти, которая, в свою очередь, не может реализовываться без силы.

М. Манн выделяет четыре источника социальной власти (силы): идеологический, экономический, военный и политический [Манн, 2014, с. 17]. В основе идеологической власти лежит потребность людей найти главный смысл в жизни, разделять нормы и цен- 
ности, а также принимать участие в эстетических и ритуальных практиках совместно с другими. Сила идеологических движений коренится в нашей неспособности добиться полноты нашего знания о мире. Экономическая сила связана с потребностями людей извлекать, трансформировать, распространять и потреблять продукцию. Военная сила представляет собой социальную организацию концентрированного (мобилизованного и сфокусированного) и летального насилия. Политическая сила - централизованное и территориальное регулирование общественной жизни. При этом базовой функцией правительства является обеспечение порядка на определенной территории [Mann, 2013, p. 2]. Однако, на наш взгляд, выделение «жесткой» и «мягкой» сил позволяет сделать анализ более эффективным за счет более емкого и одновременно простого инструментария. Дополнительное «экономическое» измерение силы может успешно рассматриваться в качестве ресурсного компонента и «жесткой», и «мягкой» сил, а политическое измерение весьма тесно связано с идеологическим аспектом.

\section{«Умная сила», «эффект колеи» и проблема институциональных изменений}

Дифференциация видов силы и власти не способна сама по себе помочь государствам справиться с коренными измерениями, протекающими в международной системе. По этой причине оптимальным представляется сочетание «жесткой» и «мягкой» сил в рамках концепции «умной силы», предложенной американским ученым Дж. Наем, который также является автором концепции «мягкой силы». «Умная сила» представляет собой сочетание «жесткой силы» для понуждения и возмездия и «мягкой силы» в виде убеждения и притяжения [Най, 2013, с. 18]. Важным элементом реализации политики «умной силы» является дефинизация (авт.) - процесс принятия решений в отношении национальных интересов, формулирования и решения ключевых задач, выбора способов и инструментов их разрешения и накопления необходимых ресурсов, а также оценки достигнутых результатов и определения новых стратегических целей и задач, в соответствии с которым в основе целеполагания лежат приоритеты обеспечения безопасности в разносрочных перспективах. «Умная сила» подразумевает использование широкого инструментария «мягкой» и «жесткой» сил, сопровождающееся постоянным высокодинамичным поиском оптимального сочетания, определяемого, как правило, ad hoc.

«Умная сила» способствует эффективному использованию комплексной взаимозависимости для решения ключевых национальных, региональных и глобальных задач и является «не только силой над другими, но и совместно с другими» [Най, 2013, с. 23]. «Умная сила» благодаря наличию компонента «мягкой силы» позволяет государствам эффективно присутствовать в идейном измерении международных отношений, оказывая воздействие на сферы, лежащие вне досягаемости их традиционных инструментов - общества и ценности. Одновременно «жесткая сила» позволяет укрепить силу образов в «реальном» измерении международных отношений - на уровне государств, сделав влияние субъекта «умной силы» более комплексным и мощным.

Непременным атрибутом также является наличие значительного числа компетенций, которые можно объединить под общим наименованием «сила управления», тесно связанным с контекстуальным интеллектом. Контекстуальный интеллект - способность понимать меняющуюся окружающую обстановку и накапливать информацию на меняющихся рынках. «Во внешней политике контекстуальный интеллект представляет собой мастерство лидера в сфере интуитивной диагностики, помогающей выстраивать 
тактику в соответствии с поставленными целями для того, чтобы создать умный план действий в зависимости от меняющейся обстановки» [Nye, 2008, p. 87]. Как пишет Дж. Най: «Контекстуальный интеллект подразумевает одновременно способность различать тенденции среди множества явлений и адаптивность в выборе возможностей воздействия на них» [Nye, 2008, p. 88].

Контекстуальный интеллект позволяет делать максимально корректный и применимый выбор в динамично изменяющейся среде. Но, как справедливо отмечает Д. Норт, фундаментальным фактором, определяющим динамику развития общества и корректирующим принимаемые решения, является «эффект колеи» [Норт, 2010, с. 83]. Он представляет собой «ограничение возможностей выбора, существующих в настоящем, основанное на историческом опыте прошлого» [Норт, 2010, с. 83]. «Эффект колеи» связан с устойчивостью и стабильностью ценностных установок общества, а также с тем, какие из аспектов накопленной информации будут оказывать влияние на процессы дефинизации.

Так, в качестве «эффекта колеи» в АТР уместно упомянуть негативное восприятие в странах макрорегиона политики Японии времен Второй мировой войны, когда японские оккупационные войска творили беззакония в отношении мирного населения государств Восточной Азии.

После окончания войны японские власти предприняли большое количество мер для изменения ситуации. Они включали в себя и мероприятия, направленные на предотвращение милитаризации политики (9-я статья Конституции, ограничивающая право Японии на ведение военных действий), и меры, направленные на стимулирование экономического развития стран региона (реализация концепции «журавлиного клина», предусматривающей постепенное перемещение производств из Японии в страны региона). Однако в обществах соответствующих государств во многом сохраняется стойкая подозрительность по отношению к настоящим целям японской политики. Кроме того, многие страны, в частности Китай или Южная Корея, полагают, что японских усилий недостаточно, чтобы искупить все то зло, что они натворили за годы Второй мировой войны. Таким образом, «эффект колеи» в этих странах по-прежнему оказывает серьезное воздействие на восприятие Японии и ее политики и дефинизацию в отношении нее.

Еще одним ярким примером «эффекта колеи» в АТР является сложившаяся после Второй мировой войны система военно-политических союзов под руководством США (например, между США и Японией, США и Южной Кореей, США и Таиландом и т.д.). Благодаря им Соединенные Штаты имеют возможность активно участвовать в обеспечении региональной безопасности, фактически выступая в роли ее гаранта. Одновременно указанный статус с достаточной степенью регулярности подвергается сомнению и попыткам пересмотра некоторыми из государств региона в зависимости от эволюции американской политики, либо генерирующей дополнительную неопределенность и риски в региональной подсистеме, либо участвующих в ограничении влияния слишком агрессивных действий некоторых центров силы - КНР или КНДР. Это приводит к тому что «колея» в отношении положительного восприятия США в регионе периодически становится совсем мелкой, а порой существенно углубляется.

В отношении важности накопленного исторического опыта с Д. Нортом солидарен и Г.В. Колодко, использующий понятие «тропинка зависимости», которая оказывает формообразующее воздействие на образ мысли людей и их понимание своего окружения [Колодко, 2011, с. 73]. Сойти с «тропинки зависимости» крайне непросто, поскольку разрыв с нею, в том случае если она мешает желанной трансформации 
и тормозит развитие, требует серьезных усилий на самых разных направлениях: от образования до политики, от перестройки ментальных конструктов до смены институтов. «Тропинки зависимости» и «эффекты колеи» оказывают определяющее воздействие на формирование системы координат «дружба - соперничество - вражда» в отношении восприятия соседних государств в рамках региональных комплексов безопасности (РКБ) ${ }^{6}$. А от нее непосредственно зависит структура соответствующего РКБ, включающая формирование в нем полюсов силы и моделей взаимоотношений между ними и определяющая динамику внутрирегиональных процессов в сфере безопасности [Buzan, Wæver, 2003, p. 49].

Однако достаточно часто нет кардинальной необходимости сходить с «тропинки зависимости» и разбивать «эффект колеи». «Успешное (экономическое) развитие происходит в тех случаях, когда наличествующая система представлений создает "благоприятную” артефактную структуру, которая может справиться с новым опытом, полученным индивидуумом и обществом, и положительно решить новые дилеммы. Неудачи случаются тогда, когда новый опыт настолько далек от артефактной структуры, сложившейся в наличествующей системе представлений, что в разуме индивидуума и в артефактной структуре общества не находится средств для решения новых проблем. Чем выше артефактная структура, тем выше вероятность того, что новые проблемы будут решены успешно» [Норт, 2010, с. 108]. Практически артефактная структура, включающая в себя не просто набор ментальных конструктов и символов, но также сложившиеся практики поведения и решения отдельных задач, может обеспечивать высокую адаптивную эффективность общества и системы принятия решений в частности. От развитой артефактной структуры зависит обучаемость и приспосабливаемость системы и эффективность понимания/познания (восприятия, интерпретации и реакции) отдельных проблем и задач с учетом нового опыта и традиционных ментальных конструктов и, как следствие, возможности и результативности политики «умной силы» применительно к предмету мировой политики.

Проблема познания, по мнению Фр. Хайека, является «проблемой поиска метода, который позволял бы в максимальной степени использовать не только знания, распределенные среди отдельных членов общества, но и способности последних к открытию и изучению нового» [Hayek, 1979, p. 190]. Способность к познанию тесно взаимосвязана с накопленным опытом, культурой и сформированной институциональной структурой. Причем на международном уровне указанная взаимозависимость проявляется особенно ярко. Именно познание позволяет приобретать информацию о происходящих процессах, обеспечивать ее корректную интерпретацию и формировать решения, позволяющие достичь поставленных целей с использованием и в рамках существующих институтов. Сами институциональные изменения базируются на постоянном тестировании институтов в ходе непрерывного процесса познания окружающего мира.

Однако познание отдельных акторов, пусть и принимающих решение относительно реализуемой политики, недостаточно для достижения стратегических целей и задач, в силу своего субъективного и относительного характера. Иное дело - коллективное познание, «являющееся фундаментальной чертой культурной эволюции и состоящее из межпоколенческого накопления знаний, орудий, отношений, ценностей и институтов, развивающихся путем выборочного устранения менее пригодных форм

${ }^{6}$ Региональный комплекс безопасности представляет собой «группу единиц, чьи основные дискурсивные процессы секьюритизации и десекьюритизации настолько взаимосвязаны, что проблемы их национальной безопасности не могут рассматриваться по отдельности друг от друга» [Buzan et al., 1998, p. 201]. 
поведения» [Норт, 2010, с. 112]. Коллективное познание тесно связано с артефактной структурой соответствующего общества. В процессе коллективного познания, объединяющего в том числе участников с различным опытом и ментальными конструктами, вырабатывается картина мира соответствующего общества, включающая в том числе систему стимулов и институциональный каркас, а также понимание целей развития и значимых благ. Аналогичные процессы происходят и на наднациональном уровне в ходе коллективного познания государств, принадлежащих к определенной международной подсистеме или системе. В данном случае выразителями внутренних процессов коллективного познания являются правящие элиты соответствующих государств, pеализующие свои властные полномочия во взаимоотношениях с другими элитами.

Как и в случае с внутригосударственными отношениями на международном уровне, влияние отдельных акторов в коллективном познании более значительно, нежели у других. «Возникающая институциональная структура определяет, кто является стратегическими акторами и как они могут осуществить свой выбор. Сложившиеся (в обществе) правила принятия решений играют решающую роль при определении того, чей именно выбор важен и почему. То, каким образом люди структурируют процесс принятия решений, определяет, чьи представления имеют значение» [Норт, 2010, с. 114].

Тем не менее существует серьезная разница во внутригосударственных и международных процессах коллективного познания, связанная с понятием суверенитета. Если во внутренней политике существует возможность не учитывать результаты познания и интересы отдельных общественных групп, то на международном уровне подобные действия встречаются значительно реже. Причина этого кроется в том, что значимость каждого отдельного актора в формировании прочной и эффективной институциональной структуры относительно более велика как в силу меньшего числа участвующих акторов, так и в силу больших деформационных возможностей каждого из них. Как показывает исторический опыт развития международных институтов, влияние политических действий отдельных акторов при прочих равных более значительно в процессах разрушения институтов, нежели созидания. То есть один и тот же объем ресурсов, потраченный на негативные и на положительные действия по отношению к институтам, приводит к более серьезным результатам при проведении негативной политики. Иными словами - ломать проще, чем строить. Правда, указанная максима в большинстве случаев касается ситуаций, когда деформирующий актор уже является участником соответствующих институтов. Актор, находящийся вне институциональной структуры, более ограничен в своих возможностях относительно нанесения вреда, нежели ее участники. Хотя и в данной ситуации есть исключения. Например, Китай для достижения своих целей в отношениях с АСЕАН регулярно обращается к проведению своей политики через отдельных членов организации, например, Камбоджу или Мьянму.

Ограничения на познание и дефинизацию как один из аспектов познания накладывают существующие институты, также сталкивающиеся с определенными ограничениями из-за «эффекта колеи». И грамотное использование подобных ограничений, обеспечивающее модулирование векторов и форм коллективного познания иных структур, является важным аспектом «умной силы». Особенно успешной она становится при обращении к культуре соответствующих целевых государств и регионов.

«Если принять широкое определение культуры, согласно которому она рассматривается как набор ценностей, верований, традиций, обычаев и т.д. (нематериальных интегрирующих паттернов. - Примеч. авт.), служащих для идентификации и связывания группы (людей) воедино, тогда нетрудно предположить, что культура будет влиять 
на то, как думают и действуют члены группы, а также на поведение группы в целом» [Тросби, 2013, с. 94-95]. Посредством культуры осуществляется межпоколенческое транспонирование прежних норм, идей и ценностей и обеспечивается адаптация к внешним вызовам через корректировку институциональной структуры. «Культура определяет формы хозяйственной и политической активности» [Колодко, 2011, с. 189] и формирует среду существования и деятельности отдельных обществ, их государств и групп государств. «Институциональные ограничения накапливаются с течением времени, так что культура общества есть кумулятивная структура правил и норм (а также убеждений. - Примеч. авт.), которая наследуется из прошлого и которая определяет настоящее и влияет на будущее» [Норт, 2010, с. 20].

В контексте реализации политики «умной силы» особую значимость приобретает связь между близкими или родственными культурами акторов, проводящих данную политику, и целевых акторов. В подобных культурах могут прослеживаться сходства в коллективном познании и системах стимулов, что способствует снижению «неизвестной неопределенности» в межакторных отношениях. Однако в случае наличия негативного опыта в рамках «эффекта колеи», например, уверенность (определенность) в том, что политика соседа регулярно приводит к генерации существенных угроз, вызовов и рисков (традиционное восприятие КНР в ряде стран Юго-Восточной Азии (ЮВА)), может формироваться запрос на поиск способов их предотвращения, связанных с увеличением «неизвестной неопределенности» (увеличение вовлечения США в региональные процессы, которое само по себе приводит к генерации новых напряженностей в отношениях стран региона с КНР).

Реакция акторов на отдельные события и результаты может приводить к институциональным изменениям. Они представляют собой структурные изменения, вносимые акторами во взаимодействия друг с другом с целью достижения определенных результатов, а также относительно случайные 7 деформации структуры, вызванные ее реакцией на соответствующие действия. В той степени, в какой институциональные изменения приводят к изменению последствий в соответствии с замыслами ответственных за это акторов, намерения и результаты совпадают друг с другом. «Огромная доля (экономических) изменений представляет собой непредвиденные последствия институциональных изменений, что является отражением значительного разрыва между намерениями и результатами, вызванного наличием «ошибочных» представлений. Их ошибочность может заключаться не только в неверном понимании ситуации, но и в том, что изменившаяся институциональная структура не влечет за собой замышлявшихся изменений поведения» [Норт, 2010, с. 120]. Если институциональный каркас сочетается с комплексной артефактной структурой, а в основе действий, направленных на достижение институциональных изменений, лежит адекватное понимание их свойств, возможных рисков и необходимых ресурсов, результаты бывают чаще всего близки к запланированным. Однако при этом расширение инструментов и знаний способствует не только разрешению проблем, но и усложнению среды и, как следствие, генерации новых «известных» и «неизвестных неопределенностей». Тем не менее основополагающую роль в процессах трансформации играет интенциональность игроков, стоящих за процессом институциональных изменений, а также их видение положения вещей. Поскольку даже случайные деформации, как правило, являются результатом спирали взаимодействия трансформируемой системы и участвующих акторов.

7 Здесь «случайные деформации» как трансформации, не являвшиеся целями первоначальных действий по изменению. 
«Институциональные изменения могут стать результатом изменений в формальных правилах, неформальных нормах или же их выполнении» [Норт, 2010, с. 21]. Важной проблемой при осуществлении институциональных изменений является недостаточность информации относительно способа эволюции неформальных сдержек и ограничений в рамках трансформируемых институциональных структур, изменение которых не связано непосредственно с соответствующим решением инициирующего актора. Некоторые из них могут возникать в результате нескоординированных действий участвующих (или не участвующих) акторов. Некоторые условности могут возникать случайным образом, а затем распространяться путем подражания или в рамках «переливания» через тесную связь культур соответствующих акторов. Многие из них дополняют, расширяют или модифицируют формальные правила. Накопленные институты приводят к созданию организаций, выживание которых зависит от сохранности этих институтов и которые будут вкладывать ресурсы, чтобы предотвратить какиелибо изменения, угрожающие их выживанию, особенно «упирая» на неформальные элементы институциональных структур. Формирование условий для эффективного воздействия на них является одним из важнейших ресурсов и одновременно целей политики «умной силы».

Так, большую роль в эффективности «умной силы» играют локальные (как местные, так и макрорегиональные) реалии ее имплементации, а также наличие акторов, формирующих среду международных отношений, их ценностное и нормативное измерение. Применительно к АТР таким актором является АСЕАН, которая задает «правила игры» в регионе, фактически реализуя собственную, коллективную «умную силу». США и Китай, несмотря на свою мощь, часто вынуждены играть по ее правилам. Отказ одной из сторон от этих правил приведет к автоматическому увеличению влияния другой. Таким образом, США и КНР вынуждены адаптировать свою «умную силу» к сформировавшейся региональной среде. Однако политика Китая и США, особенно в последние годы, привела к серьезной эрозии самой АСЕАН, притом что механизмы, в которых она играет ключевую роль, увеличивают свою эффективность. В регионе наблюдается ситуация, когда сам создатель региональных механизмов теряет свое влияние на фоне роста их эффективности.

\section{«Лица силы» и безопасность как доминанта международных отношений}

Можно выделить четыре основные сферы приложения политики «умной силы»:

- противодействие влиянию соперничающих акторов;

- повышение влияния на соперничающих акторов;

- повышение влияния на несоперничающих акторов;

- повышение влияние в рамках подсистемы/системы международных отношений.

Практически всю совокупность отношений, возникающих в ходе применения «умной силы», можно, так или иначе, определить через вышеуказанные сферы. При этом функции отдельных видов и типов силы также могут выступать в роли значимого объекта изучения, поскольку от этого зависит эффективность и адекватность применяемой стратегии. Стоит различать особенности связей, на которые оказывается воздействие, в случае их наличия. Взаимозависимость состоит из краткосрочной восприимчивости и долгосрочной уязвимости. Восприимчивость затрагивает количество и темпы воздействия взаимной зависимости, т.е. как быстро изменения в одной части 
системы приводят к изменениям в другой части. Уязвимость входит в число относительных издержек меняющейся структуры системы взаимозависимости. Уязвимость в том числе зависит от способности общества или субъектов дефинизации своевременно реагировать на любые изменения.

Интересным концептом, позволяющим проанализировать функции отдельных видов и типов силы в рамках концепции «умной силы», является выделение «трех лиц силы», которые оказывают влияние на формирование условий для реализации интересов субъекта «умной силы» посредством воздействия на предпочтения объекта воздействия «умной силы». Все «три лица силы» были сведены в единый концепт уже упоминавшимся Дж. Наем.

Первое лицо силы связано со способностями и возможностями актора - источника силы заставить других акторов действовать неким образом, который противоречит их первоначальным намерениям и планам действий. Чаще всего интерпретация силовых возможностей акторов осуществляется именно в данном разрезе. Если наложить указанное определение силы на известную метафору Г. Моргентау об отношениях государств на международной арене как бильярдных шаров, то получится, что на «глобальном бильярдном столе» некоторые из шаров весят больше и имеют больший размер. По этой причине их сложнее привести в движение, а при столкновении с другими, менее крупными шарами, те, в свою очередь, «отскакивают» значительно дальше и с большей скоростью. Внимание на этот аспект силы было обращено, к примеру, в классической работе Р. Даля «Кто правит: демократия и сила в американском городе» [Dahl, 1961], ставшей развитием его идей, высказанных еще в критической статье на работы Ч. Миллса [Mills, 1956] и Ф. Хантера [Hunter, 1953] по проблемам роли элиты в формировании политики, носящей название «Критика модели правящей элиты» [Dahl, 1958, p. 463-469].

Проблема второго лица силы была затронута в упоминавшейся работе Ф. Хантера «Силовая структура сообщества: изучение принятия решений» [Hunter, 1953]: в качестве целей «людей, обладающих реальной властью», отмечался контроль над недопущением «публичных дискуссий по любым вопросам, кроме тех, что одобрены властной группировкой» [Hunter, 1953, p. 246-249]. Второе лицо силы оказывает воздействие на формирование и установки цепочки действий акторов-объектов, т.е. возможности реализации тех или иных приоритетов и целей соответствующих акторов. По сути, ставится цель не допускать вынесения и формирования условий для реализации предпочтений, которые противоречат целям и задачам субъекта «умной силы» [Bachrach, Baratz, 1963, p. 632-642]. Так, это может выражаться в установке правил игры, ограничивающих возможные программы действий и результаты решений для участников, которые присоединяются к установленному механизму, например, международной организации. С.А. Афонцев в своей работе, посвященной политическим рынкам, пишет, что «решения, принимаемые на более высоких уровнях, ограничивают набор для реализации на более низких уровнях» [Афонцев, 2010]. Например, при присоединении к АСЕАН соответствующая страна региона должна автоматически принимать согласованные «условия и правила игры», накладывающие определенные ограничения на ее поведение как в рамках самой организации, так и вне ее. Не обязательно, что такие правилаограничения установлены кем-то из акторов исключительно в своих интересах. Просто в рамках реализации «умной силы» актором, включающим в себя сразу несколько участников, осознанно или нет может ставиться задача по ограничению негативных воздействий от участия акторов (внутренних и внешних) в их механизме/механизмах. Также причиной может быть результат коллективных согласований как максимальный 
возможный результат, ради которого страны не готовы отказываться от наложения дополнительных ограничений на свои действия, но который позволяет добиться максимального результата в достижении коллективных целей, сформулированных на момент принятия установочного решения. При этом факта наложения ограничений присоединяющиеся акторы могут и не замечать.

Третье лицо силы подразумевает воздействие идей, убеждений и ценностей на формирование изначальных предпочтений иных акторов. Это позволит формировать их предпочтения таким образом, чтобы потом они совпадали с целями источника «умной силы» [Льюкс, 2010]. В данном случае проблема заключается в том, чтобы в условиях отличной ценностной системы координат и иного культурного кода сформировать такие условия и ориентиры развития, которые удовлетворяют задачам достижения стратегических целей источника силы и одновременно не являются чужеродными и неприемлемыми с точки зрения краткосрочных и среднесрочных целей объекта ее применения. Чтобы установить правила и возможности для формирования положительной интенциональности, необходимо обеспечить эффективное транспонирование желаемых идей, убеждений и ценностей в первую очередь на уровень элит, принимающих значимые политические решения. Одновременно для достижения комплексного долгосрочного эффекта необходимым условием является распространение действия целевых идеологических конструктов на широкие общественные массы. Если указанный маневр удается осушествить, то в будущем общество, привитое таким «геном», будет само оказывать влияние на формирование властной элиты и осуществлять контроль за ее деятельностью в рамках системы координат, заданной внешними участниками.

Важным элементом политики «умной силы» является комплексная стратегия, включающая в себя выбор и оптимизацию ресурсов, постановку планов в соответствии с предпочтениями, практическую часть по достижению результатов и анализ достигнутых результатов. Разумеется, число звеньев можно существенно расширить. Стоит отметить, что связь предпочтений и планов весьма тесна. Предпочтения определяют значимость и очередность целей действия, а планы определяют усилия актора, которые он предпринимает для достижения желаемых результатов в соответствии с заранее определенной программой и последовательностью действий [Най, 2013].

Среди предпочтений и приоритетов государства на первом месте всегда стоит безопасность, а остальные аспекты государственной политики в той или иной степени подчинены ее обеспечению. Таким образом, принципиальное значение имеют процессы формирования набора приоритетов национальной безопасности и комплекса мер по их достижению [Афонцев, 2010, с. 320]. Национальная безопасность выступает в роли синтетического понятия, объединяющего совокупность предпочтений и приоритетов государства в выработке и реализации своей комплексной стратегии. Она рассматривается в контексте обеспечения базовых условий реализации ключевых интересов в политической, экономической, социальной, культурной и других сферах, относительно достижения которых в обществе существует устойчивый консенсус [Афонцев, 2010, c. 21]. Выработка указанного консенсуса осуществляется в рамках процессов секьюритизации ${ }^{8}$ и дефинизации. И, как подчеркивает Роб Уокер, «значение понятия безопасности привязано к исторически конкретным формам политического сообщества»

${ }^{8}$ Секьюритизация - дискурсивный процесс, посредством которого в политическом сообществе формируется восприятие того или иного фактора в качестве значимой угрозы, а также понимание необходимости по принятию срочных исключительных мер по ее разрешению, и выражается соответствующий призыв [Buzan, Wæver, 2003, p. 491]. 
[Walker, 1990]. В общетеоретическом же контексте применительно к настоящему исследованию повышение безопасности может трактоваться как снижение неопределенности в ее отношении, например, при помощи введения определенных ограничений и запретов как способа организации пространства. Практически применительно к внешнеполитическим процессам в рамках отдельных международных подсистем снижение неопределенности выступает в роли основной доминанты, определяющей интенциональность участвующих акторов по отношению к динамике соответствующих процессов. В данном контексте даже негативный опыт взаимодействия с соучаствующими акторами и сложившаяся устойчивая система комплексного взаимовосприятия в рамках системы координат «вражда - дружба - соперничество» являются крайне полезными. Указанная информация позволяет снизить уровень «неизвестной неопределенности» в отношениях между акторами и, соответственно, сэкономить существенные ресурсы для предотвращения возможных нежелательных действий, благодаря отсутствию необходимости растрачивания ресурсов на поиск возможных угроз в смежных областях.

В анализе процессов обеспечения безопасности и принятии соответствующих решений весьма важным остается вопрос узкой или широкой интерпретации понятия «безопасность». Многое зависит от желаемых целей и субъективных особенностей акторов. Если брать исключительно уровень государства, то в первую очередь речь будет идти о традиционной, военно-политической безопасности. Если в качестве объекта политики обеспечения безопасности рассматриваются общество и индивидуумы, то резко повышается значимость нетрадиционных аспектов безопасности. Невозможность тотальной безопасности заставляет искать баланс между интересами общества и государства, что создает динамику политического процесса и - опосредованно - внешнеполитического. Указанное взаимодействие переходит на уровень международных подсистем и международной системы, где государства предстают в виде условно рядовых акторов - своего рода «государственных индивидуумов». Поиску баланса оказываются подчинены их взаимодействия во всем спектре международной деятельности.

Однако «государства государств» не существует, поскольку нет «надвнешней сферы». Государство в международной системе выступает в качестве механизма самоидентификации общества и обеспечивает его отделение от других обществ и государств. Создаваемые формальные и неформальные правила и механизмы, проявляющиеся в виде институтов, ограничивают свободу государств, помогая упорядочить их взаимодействие, что в той или иной степени соответствует их интересам. Тем не менее существуют серьезные риски чрезмерного ограничения и зарегулированности взаимодействий под воздействием «эффекта колеи», особенно если иметь в виду международные отношения как межгосударственные. Результатом таких действий может служить консервация существующих проблем и «закупоривание» каналов эффективного взаимодействия, что также может приводить к тому, что ускоряющаяся динамика взаимодействий может привести к взрыву сложившихся институциональных структур. Соответственно, возникает стратегическая задача нахождения «золотой середины» между свободой и упорядоченностью отношений, проблемами и безопасностью.

На уровнях региональных подсистем и глобальной системы на первый план выходит интерпретация приоритетов международной безопасности как комплексных политико-экономических благ. Приоритеты и цели развития международной системы на региональном и глобальном уровнях не являются простой суммой национальных интересов участвующих государств, часто находясь в определенном противовесе с интересами отдельных государств. Причина этого достаточно проста - в ряде случаев достижение общих интересов требует компромиссного решения. Причем по некоторым, 
особенно важным вопросам необходимым условием эффективного сотрудничества также является консенсус в выработке оптимального решения проблемы между всеми участниками. Умение извлекать максимальные выгоды из ситуаций, когда необходимо идти на уступки и ограничивать собственные притязания, и является отличительной чертой «умной силы». Особенно важным является данное умение для акторов, стремящихся проводить политику коллективной «умной силы», таких как АСЕАН.

Объединение коллективных усилий, сопряженное с серьезной задачей соотнесения ключевых интересов и целей отдельных акторов, способствует накоплению серьезных ресурсов и компетенций и проведению эффективной трансформации институциональной структуры. Как пишет Д. Норт, «источник институциональной инновации основывается на “C-D” разрыве , т.е. разрыве между компетентностью агента и сложностью задачи принятия решений. Сталкиваясь с таким разрывом, агент (индивидуальный или коллективный. - Примеч. авт.) будет определять правила для того, чтобы ограничить число вариантов выбора в подобных ситуациях» [Норт, 2010, с. 28]. Соответственно, будут продолжать возникать вопросы относительно того, кто будет создавать соответствующие правила, в чьих интересах и какие при этом преследуются цели? Крайне интересными представляются также ситуации, когда институты, сформированные одними акторами в своих интересах, приносят более значительную выгоду от участия для других акторов. Подобная ситуация наблюдается в функционировании ряда механизмов повышения безопасности, действующих в АТР, Регионального форума АСЕАН по проблемам безопасности (АРФ) в частности. Умение использовать такие возможности первоначально «чужих» институтов и составляет суть политики «умной силы», позволяющей максимально уменьшить разрывы между компетентностью актора и сложностью решаемой задачи, а также его намерениями и достигаемым результатом.

\section{Заключение}

В современном динамичном мире международным акторам, особенно государствам, очень непросто сохранять свою эффективность. Увеличение числа участников и изменение природы международных отношений, расширение форм и видов взаимодействия между ними приводят к возникновению огромных зон неопределенности, преодоление которых часто требует колоссальных ресурсов. Уменьшению или элиминированию неопределенности служат многочисленные институты, в основе которых в той или иной степени лежат убеждения ключевых акторов, питательной средой которых является культура, также являющаяся проявлением накопленного исторического опыта соответствующих обществ. Сама институциональная структура является «комбинацией формальных правил, неформальных ограничений и особенностей их выполнения». Особенности выполнения обусловлены существующей системой стимулов, механизмами побуждения (принуждения) и особенностями процесса понимания/ познания, также тесно связанного с накопленным опытом и артефактной структурой. Исторический опыт, накопленный в ходе развития отдельных обществ и государств, приводит к формированию «эффекта колеи» - «ограничения возможностей выбора, существуюших в настоящем, основанного на историческом опыте прошлого». Все это в совокупности находит отражение в организации комплекса взаимодействий на международной арене.

\footnotetext{
${ }^{9}$ Англ. C-D: Competence-Difficulty (компетентность - сложность).
} 
Государства и сегодня продолжают оставаться ключевыми международными акторами. Однако они испытывают острую потребность в действенных средствах влияния как на другие государства, так и на отдельные сообщества людей. Для достижения целей своей политики они вынуждены расширять ее арсенал, прибегая к инструментам «жесткой» и «мягкой» сил, которые под воздействием «силы управления» и развитого контекстуального интеллекта могут интегрироваться в рамках «умной силы». При этом определяющую роль в формировании «умной силы» играют процессы коллективного познания/понимания, одним из элементов которого является дефинизация. Она представляет собой процесс принятия решений в отношении национальных интересов, формулирования и решения ключевых задач, выбора способов и инструментов их разрешения и накопления необходимых ресурсов, а также оценки достигнутых результатов и определения новых стратегических целей и задач, в соответствии с которым в основе целеполагания лежат приоритеты обеспечения безопасности в разносрочных перспективах. Фактически обеспечение безопасности выступает в роли ключевого приоритета деятельности любого государства на международной арене, с учетом которого и происходит реализация политики «умной силы».

В АТР политика «умной силы» не является приоритетом какого-то одного актора: к ней обращаются и крупнейшие государства, как КНР, и значимые надгосударственные акторы, как АСЕАН. Более подробно процессы применения «умной силы» в АТР будут рассмотрены в статье «Счастье от разума: «умная сила» КНР и ее влияние на развитие архитектуры безопасности в Азиатско-Тихоокеанском регионе», которая будет опубликована в одном из ближайших номеров журнала.

\section{Литература}

Афонцев С.А. (2010) Политические рынки и экономическая политика. М.: КомКнига.

Братерский М.В. (2013) Сила денег в современном мире // Лики силы. Интеллектуальная элита России и мира о главном вопросе мировой политики / под ред. С.А. Караганова, Т.В. Бордачева. М.: Международные отношения.

Грейф А. (2013) Институты и путь к современной экономике. Уроки средневековой торговли. М.: Изд. дом Высшей школы экономики.

Караганов С.А., Лукьянов Ф.А. (2013) Россия в мире силы XXI века // Лики силы. Интеллектуальная элита России и мира о главном вопросе мировой политики / под ред. С.А. Караганова, Т.В. Бордачева. М.: Международные отношения.

Колодко Г. (2011) Глобализация, трансформация, кризис - что дальше? М.: Магистр, 2011.

Льюкс С. (2010) Власть: радикальный взгляд. М.: Изд. дом Высшей школы экономики.

Манн М. (2014) Власть в ХХІ столетии: беседы с Джоном А. Холлом. М.: Изд. дом Высшей школы экономики.

Михневич С.В. (2014) Панда на службе Дракона: основные направления и механизмы политики «мягкой силы» Китая // Вестник международных организаций. № 2. Режим доступа: http://iorj.hse. ru/2014-9-2/125047954.html (дата обращения: 21.10.2015).

Михневич С.В. (2015) Мудрец помогает Поднебесной: развитие сети Институтов Конфуция как инструмент реализации политики «мягкой силы» КНР в Большой Восточной Азии // Вестник международных организаций. № 1. Режим доступа: http://iorj.hse.ru/2015-10-1/147908972.html (дата обращения: 21.10.2015).

Морозов В. (2009) Россия и Другие: идентичность и границы политического сообщества. М.: Новое литературное обозрение.

Най Дж. (2013) Будущее власти. М.: АСТ. 
Норт Д. (2010) Понимание процесса экономических изменений. М.: Изд. дом Высшей школы экономики.

Талеб Н. (2009) Черный лебедь: под знаком непредсказуемости. М.: Колибри.

Тросби Д. (2013) Экономика и культура. М.: Изд. дом Высшей школы экономики.

Эйсбур Фр. (2013) Сила оружия - винтовка и власть // Лики силы. Интеллектуальная элита России и мира о главном вопросе мировой политики / под ред. С.А. Караганова, Т.В. Бордачева. М.: Международные отношения.

Bachrach P., Baratz M. (1963) Decisions and Non-decisions: Analytical Framework // American Political Science Review. Vol. 57. No. 3.

Buzan B., Weaver O., Wilde J. de (1998) Security: A New Framework for Analysis. L.: Lynne Rienner Publishers.

Buzan B., Wæver O. (2003) Regions and Powers: The Structure of International Security. N. Y.: Cambridge University Press.

Dahl R.A. (1958) Critique of the Ruling Elite Model // American Political Science Review. No. 52.

Dahl R.A. (1961) Who governs: Democracy and Power in an American City. New Haven, CT: Yale University Press.

DiMaggio P., Hargittai E. (2001) From the "Digital Divide" to "Digital Inequality": Studying Internet Use as Penetration Increases. Working Paper. No. 15. Princeton University.

Hayek F.A. (1979) Law, Legislation and Liberty. Vol. 3. Chicago: University of Chicago Press.

Hunter F. (1953) Community Power Structure: A Study of Decision Makers. Chapel Hill NC.: University of North Caroline Press.

Knight F.H. (1921) Risk, Uncertainty and Profit. Boston MA: Hart, Schaffner and Marx; Houghton Mifflin.

Mann M. (2013) The Sources of Social Power. Vol. 4. Globalizations, 1945-2011. Cambridge University Press.

Mills Ch. W. (1956) The Power Elite. N. Y. : Oxford University Press.

Nye Js. (2004) Soft power. The Means to Success in World Politics. N. Y.: Public Affairs.

Nye Js. (2008) The Power to Lead. Oxford: Oxford University Press.

Walker R.B.K. (1990) Security, Sovereignty and the Challenge of World Politics // Alternatives. Vol. 15. No. 1. 


\title{
Smart Power in Institutionalization of International Relations
}

\author{
S. Mikhnevich
}

Sergey Mikhnevich - PhD student in the Division of International Relations, National Research University Higher School of Economics; 20 Myasnitskaya, 101000 Moscow, Russian Federation; E-mail: sxzex@yandex.ru

\begin{abstract}
The article analyzes the smart power factor in institutional changes in international relations, the main elements and features, and the importance of interaction on the issue of "power" in the evolution of international system and subsystems. International relations is currently in a process of transformation, related to the dramatic increase in opportunities for transborder interaction among different communities and social groups. The result could be the creation of the new identity that exists beyond the states' borders. The wide practice of the transborder contacts increases the significance of values and ideology in international interaction. At the same time, the background for the transformation of international relations is the globalization that exacerbates the socioeconomic divide, the political divide and the value divide. As the result, there is an exponential increase in global political uncertainty and the international weakness of states. One effective remedy to systematize interactions and eliminate uncertainty is the establishment of complex institutional structures, which reflect the convictions and values of societies and communities in the course of history. Therefore, building appropriate institutes can significantly ease many existing international problems, including ones connected with the changing international environment. Another important thing is to provide mutual benefits for all involved actors. Otherwise, the established systems would not be significantly efficient. The decrease in the international capacities of the states also appears in the decrease of the hard power source to promote national interests. The significance of soft power is constantly rising. However, soft power does not involve direct action regarding the politics of other states. Smart power, which combines hard power for compulsion and vengeance and soft power for persuasion and attraction, is more effective and adequate. An actor's capacity to promote smart power is closely linked with contextual intellect and existing path dependence rooted in culture and historical experience, which shapes the collective cognition and perception of events and occurrences. Such factors directly influence the process of international institutionalization. In analyzing smart power aspects, this article draws attention to the concept of the "three faces of power." In addition, it points out the determinant meaning of security in international processes, which accounts for most important decisions of elites in the process of definization, the process of decision making regarding the national interests. Improving security can be treated as decreasing uncertainty, including by means of institutionalization and collective smart power implementation.
\end{abstract}

Key words: smart power, soft power, hard power, uncertainty, culture, strategy, institutional changes, definization, securitization, security, China, United States, ASEAN, South-East Asia, Asia-Pacific region

\section{References}

Afoncev S.A. (2010) Politicheskie rynki i jekonomicheskaja politika [Political Markets and Economic Policy]. Moscow: KomKniga.

Bachrach P., Baratz M. (1963) Decisions and Non-decisions: Analytical Framework. American Political Science Review, vol. 57, no 3.

Braterskij M.V. (2013) Sila deneg v sovremennom mire [Power of Money in the Modern World]. Liki sily. Intellektual'naja jelita Rossii i mira o glavnom voprose mirovoj politiki [Faces of Power: Intellectual Elite of Russia and the World and the Most Important Question of World Politics] (eds. S.A. Karaganov, T.V. Bordachev). M.: Mezhdunarodnye otnoshenija.

Buzan B., Wæver. O. (2003) Regions and Powers: The Structure of International Security. N.-Y.: Cambridge University Press.

Buzan B., Weaver O., de Wilde J. (1998) Security: A New Framework for Analysis. London: Lynne Rienner Publishers. 
Dahl R.A. (1961) Who governs: Democracy and Power in an American City. New Haven, CT: Yale University Press.

Dahl R.A. (1958) Critique of the Ruling Elite Model. American Political Science Review, no 52.

DiMaggio P., Hargittai E. (2001) From the «Digital Divide» to «Digital Inequality»: Studying Internet Use as Penetration Increases. Working Paper, no 15. Princeton University.

Grejf A. (2013) Instituty i put' $k$ sovremennoj jekonomike. Uroki srednevekovoj torgovli [Institutions and the Path to the Modern Economy: Lessons from the Medieval Trade]. Moscow: HSE Publishing House.

Hayek F.A. (1979) Law, Legislation and Liberty, vol. 3. Chicago: University of Chicago Press.

Hunter F. (1953) Community Power Structure: A Study of Decision Makers. Chapel Hill NC.: University of North Caroline Press.

Jejsbur Fr. (2013) Sila oruzhija - vintovka i vlast' [The Power of Weapon - Gun and Power]. Liki sily. Intellektual'naja jelita Rossii i mira o glavnom voprose mirovoj politiki [Faces of power: Intellectual Elite of Russia and the World and the Most Important Question of World Politics] (eds. S.A. Karaganov, T.V. Bordachev). M.: Mezhdunarodnye otnoshenija.

Karaganov S.A. Luk'janov F.A. (2013) Rossija v mire sily XXI veka [Russia in the World of Power in the $21^{\text {st }}$ Century]. Liki sily. Intellektual'naja jelita Rossii i mira o glavnom voprose mirovoj politiki [Faces of power: Intellectual Elite of Russia and the World and the Most Important Question of World Politics] (eds. S.A. Karaganov, T.V. Bordachev). M.: Mezhdunarodnye otnoshenija.

Knight F.H. (1921) Risk, Uncertainty and Profit. Boston MA: Hart, Schaffner and Marx; Houghton Mifflin. Kolodko G. (2011) Globalizacija, transformacija, krizis - chto dal'she? [Globalization, Transformation, Crisis and What Next?] Moscow: Magistr.

Lukes S. (2010) Vlast': radikal'nyj vzgljad [Power a Radical View]. Moscow: HSE Publishing House.

Mann M. (2013) The Sources of Social Power, vol. 4, Globalizations, 1945-2011. Cambridge University Press.

Mann M. (2014) Vlast'v XXI stoletii: besedy s Dzhonom A. Hollom [Power in the 21st Century. Conversations with John Hall]. Moscow: HSE Publishing House.

Mikhnevich S. (2014) Panda na sluzhbe Drakona: osnovnye napravleniya i mekhanizmy politiki «myagkoy sily» Kitaya [The Panda in the Dragon's Service: The Main Directions and Mechanisms of China's Soft Power Policy]. International Organisations Research Journal, vol. 9, no 2 (in Russian). Available at: http://iorj.hse.ru/ en/2014-9-2/125047954.html (accessed 21 October 2015).

Mikhnevich S. (2015) Mudrets pomogaet Podnebesnoy: razvitie seti Institutov Konfutsiya kak instrument realizatsii politiki «myagkoy sily» KNR v Bol'shoy Vostochnoy Azii [The Sage Helps the Celestial Empire: Promotion of the Confucius Institutes' Global Network as an Instrument of the PRC's Soft Power Policy in the Great Eastern Asia Region]. International Organisations Research Journal, vol. 10, no 1 (in Russian). Available at: http://iorj.hse.ru/2015-10-1/147908972.html (accessed 21 October 2015).

Mills Ch. W. (1956) The Power Elite. N.Y.: Oxford University Press.

Morozov V. (2009) Rossija i Drugie: identichnost' i granicy politicheskogo soobshhestva [Russia and the Others: Identity and Limits of the Political Community]. Moscow: Novoe literaturnoe obozrenie.

Naj D. (2013) Budushhee vlasti [The Future of Power]. Moscow: AST.

Nort D. (2010) Ponimanie processa jekonomicheskih izmenenij [Understanding the Process of Economic Change]. Moscow: HSE Publishing House.

Nye Js. (2004) Soft power. The Means to Success in World Politics. N.Y.: Public Affairs.

Nye Js. (2008) The Power to Lead. Oxford: Oxford University Press.

Taleb N. (2009) Chernyj lebed': pod znakom nepredskazuemosti [The Black Swan: the Impact of the Highly Improbable]. Moscow: Kolibri.

Trosbi D. (2013) Jekonomika i kul'tura [Economics and Culture]. Moscow: HSE Publishing House.

Walker R.B.K. (1990) Security, Sovereignty and the Challenge of World Politics. Alternatives, vol. 15, no 1. 